\title{
Taxonomic utility of female copulation organs in Sericini chafers (Coleoptera, Scarabaeidae), with special reference to asymmetry
}

\author{
Alev Özgül-Siemund ${ }^{1}$, Dirk Ahrens ${ }^{1,2}$ \\ ${ }^{1}$ Zoologisches Forschungsmuseum A. Koenig, Adenauerallee 160, 53113 Bonn, Germany \\ ${ }^{2}$ E-mail:d.ahrens@zfmk.de
}

Key words: beetles, female genitalia, integrative taxonomy, Melolonthinae, morphology

\begin{abstract}
Female genitalia are widely underrepresented in taxonomic studies. Here we investigate the morphological variation among female copulation organs for a group of scarab beetles (Sericini) with similar ecology, external morphology and copulation mechanics. We examined traits qualitatively and quantitatively based on 80 and 18 species (genus Pleophylla), respectively. Additionally we explored whether female genitalia are affected by asymmetry. The vast diversity of slerotised structures including their shapes illustrated the high taxonomic and phylogenetic utility of female genitalia in this group. The morphometric analysis of Pleophylla, confirmed that sclerotisations in the ductus bursae are very suitable for species-level taxonomic purposes. Stable interspecific variation is more hardly discernable in other parts such as the vaginal palps (shape and size) or the other membranous structures such as the shape of the bursa copulatrix. Asymmetric genitalia that arose multiple times independently among insects are found in most of the examined Sericini species. Asymmetries regarded either the bursa copulatrix, or both the bursa copulatrix and ductus bursae and comprised sclerotised and non-sclerotised structures being most common in modern Sericini. Here, highly asymmetric sclerotised structures are linked with strong asymmetry of the male copulation organs. Widespread asymmetry among megadiverse Sericini with a complex male-female genital asymmetry suggests that the shift to asymmetry is phylogenetically rather conserved. From the range of hypotheses, sexual selection seems to be the most reasonable to explain the evolution and stability of asymmetry in chafer genitalia.
\end{abstract}

\section{Contents}

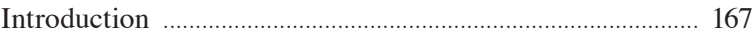

Material and methods …………………………………...... 168

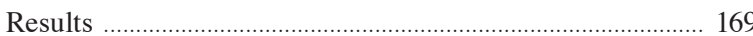

General morphology and inter-specific variation

in female genitalia of Sericini ........................................... 169

Case study - Interspecific variation among

Pleophylla species ……….................................................... 173

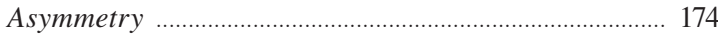

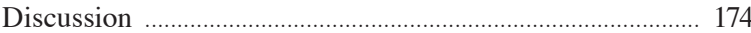

Utility of female genitalia for taxonomy and

systematics

174
Symmetry and asymmetry ……………………................ 175

Acknowledgements .................................................................. 176

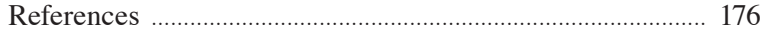

\section{Introduction}

Male genitalia are considered one of the most important and useful species-diagnostic characters in insect systematics. In many insects, genitalia often provide the only way to reliably distinguish species using morphology. The diversity of male genitalia and their pattern of morphological variation is a well-documented phenomenon in evolutionary biology (Hosken and Stockley, 2004). Sexual characters often show particularly great 'species-specific' variation and can play an important role in reproductive isolation and speciation processes (Wojcieszek and Simmons, 2013). This diversity of shapes is often linked to evolutionary factors and selection processes that might contribute to a rapid and divergent evolution of genital morphology (Mayr, 1963; Eberhard, 1985, 1996; Arnqvist and Thornhill, 1998; Hosken and Stockley, 2004).

Despite this crucial role of male genitalia for taxonomy, it has been repeatedly pointed out that the poor knowledge of female genitalia (in particular in terms of infraspecific and interspecific variation but also of degree of asymmetry) is seriously hampering a more comprehensive understanding of genital evolution (Mendez and Cordoba-Aguilar, 2004; Cordoba-Aguilar, 2010; Ah-King et al., 2014). Increasingly, studies report species-specific variation in female genital morphology and its coevolutionary divergence with male genital morphology (Yassin and Orgogozo, 2013; Simmons, 2014).

Symmetry and asymmetry are an essential part of the pattern of that huge variation (Huber, 2010; Schilthuizen, 2013). Asymmetries are an interesting phenomenon in otherwise bilaterally symmetric organisms 
with the potential impact to improve our understanding of fundamental evolutionary processes like the evolution of development and the selection for morphological novelties caused by behavioural changes. Asymmetry has arisen multiple times independently among insects (Schilthuizen, 2013). Several hypotheses have been proposed to explain the evolution of asymmetric structures in genitalia (Huber, 2010; Schilthuizen, 2013). Proposed advantages of asymmetric genitalia due to mating position (Huber et al., 2007; Huber, 2010) do not appear likely for scarab chafers, as all species have the same mating position (male above female and a constant mating angle). Functional differences in the left and the right side can also be rejected, since both parameres in the Coleoptera form a functional unit as a clasping organ and do not perform different tasks (Sharp and Muir, 1912). Therefore, sexual selection may be the best explanation for the evolution of shape divergence between the right and left side of genitalia among chafers.

Here we investigate the infra- and interspecific morphological variation among female copulation organs for a group of scarab beetles (Scarabaeidae: Sericini) with similar ecology, external morphology and copulation mechanics, and explore generally, whether and to what degree female genitalia are affected by asymmetry which has been widely reported so far only in male beetle specimens (Huber et al., 2007; Ahrens and Lago, 2008; Breeschoten et al., 2013). Furthermore, we are interested if and which character traits are useful to be utilized in systematics and species' taxonomy.

Sericini is a highly diverse group with nearly 4000 species in about 200 genera (Ahrens, 2006b), which is traditionally placed into the subfamily of Melolonthinae (Smith, 2006). The monophyly of Sericini has been proven in several studies (Ahrens, 2006b; Ahrens and Vogler, 2008; Ahrens et al., 2011) and the relationships of the major lineages are roughly understood. Adults of Sericini are polyphagous herbivores and feed on a variety of plant species. The larvae, known also as 'white grubs', feed on roots and underground stems of living plants (Ritcher, 1966). Some species of Sericini are economically important crop pests. Most of the more derived species show a very significant asymmetry in male copulatory organs (Ahrens and Lago, 2008).

The earliest documented studies on female internal reproductive organs of scarab beetles are those of Stein (1847) and Tanner (1927). Subsequently, many additional species were characterized (e.g. Willimzik, 1930; Heymons, 1930; Williams, 1945; Krause, 1947;
Dajoz, 1972; Dupuis 2005; Imelda Martinez and Trotta-Moreu, 2010). While female genitalia are frequently used for taxonomic purposes in dung beetles (Zunino, 1971, 1972; Martin-Piera, 1992), most previous works on melolonthines (and other pleurostict scarabaeidae) studied the morphology only for a limited number of species in detail without applying comparative criteria valuable for taxonomic purposes (e.g. Straus-Dürckheim, 1828; Menees, 1963; Watt, 1971; Berberet and Helms, 1972; Barratt and Campbell, 1982; Stringer, 1988). There are a handful of studies that focused on variation in the female genital morphology in pleurostict scarabs and used it for species taxonomy and systematics (e.g. Coca-Abia and Martin-Piera, 1991; CocaAbia et al., 1993; Coca-Abia and Robbins, 2006, Micó and Galante, 2000; Riley and Wolfe, 1995; Ahrens, 2000, 2001, 2006a,b, 2007; Ahrens and Fabrizi, 2009; Woodruff and Sanderson, 2004; Polihronakis, 2007; Zorn, 2011); however no one have accounted so far for issues of asymmetry.

\section{Material and methods}

The samples of females of approximately 80 species were mainly taken from dried museum specimens that required softening in hot water for dissection of the genitalia. Additionally we included ethanol preserved specimens for a few taxa. Samples were drawn from basal and more derived lineages of Sericini (Ahrens and Vogler, 2008) and included the genera Astaena, Paratriodonta, Omolaplia, Pleophylla, Heteroserica, Leuroserica, Leucoserica, Sericania, Cycloserica, Nepaloserica, Taiwanoserica, Serica, Pachyserica, Gynaecoserica, Lasioserica, Amiserica, Neoserica (s.str.), Chrysoserica, Calloserica, Eumaladera, and Maladera.

For all species, at least two specimens were examined. Every specimen was provided with an identification number in order to be able to associate individuals and images. Sampling was based on specimens from the following museums: Ditsong (formerly Transvaal) Museum Pretoria (TMSA), South African National Collection of Insects, Pretoria (SANC), Royal Museum for Central Africa Tervuren (RMCA), Museum für Naturkunde Berlin (ZMHB) and Zoological Research Museum A. Koenig Bonn (ZFMK).

The dissection and preparation of female genitalia followed the preparation methods of Konstantinov (1998) and involved particular attention in order to avoid destruction of soft tissue parts. After softening the specimen, the abdomen was carefully removed 
from the body with a fine forceps. The pleuron was cut to allow an opening of sternites and tergites including the pygidium. The genitalia were carefully detached from the latter. After dissection of the genitalia the abdomen was glued onto a piece of paper with the pinned specimen. Dissected genitalia were relaxed in $10 \%$ potassium hydroxide (KOH) for about 15 to $20 \mathrm{~min}$ utes (depending on the condition of the tissues) in order to remove soft tissues from the genitalia. All female genitalia were stored in glycerol in a microvial attached to the pinned specimen. In a final step, genitalia were stained with chlorazol-black before being soaked in acetic acid for several minutes.

For digital imaging, genitalia were mounted on microscope slides using a standardized amount (one drop) of glycerin or glycerin-gelatin as a mounting medium. Digital images of female genitalia were taken in dorsal view with a Zeiss discovery V20 stereomicroscope using a unique magnification (23.5x).

For the genus Pleophylla we investigated as an example study case inter- and infraspecific variation more in detail using a much wider infraspecific sampling for the 18 included species. For this objective, additional Pleophylla specimens were collected during fieldwork in South Africa, which were identified partly by matching with confidently identified male specimens using a mitochondrial DNA marker (Coxl 3-prime end) (data not shown here). The shape of the sclerotised area of the ductus bursae (dorsal view) was analyzed quantitatively using Standard Eigenshape analysis (Lohmann, 1983; McLeod, 1999) as implemented in the program PAleontological STatistics, PAST.v2.10 (Hammer et al., 2001). Outlines were digitized using TpsDIG v2.10 (Rohlf, 2006) with a graphic tablet as closed outlines by 100 semi-landmarks drawn manually. The start and end points that defined homology across specimens (Lohmann and Schweitzer, 1990) and the distance between semi-landmarks were identical. The scores with $95 \%$ of cumulative variation were used for subsequent Canonical Variate analysis (CVA) to investigate the morphospace and possible groupings of the specimens.

\section{Results}

General morphology and inter-specific variation in female genitalia of Sericini

The female reproductive organ is composed of the accessory gland, the vaginal palps, the vagina, the ductus bursae, bursa copulatrix, spermatheca, spermathecal gland, and the median oviduct (Fig. 1). The accessory glands open into the cloaca with a common, slightly tubuliform duct which represents one of the functionally most outstanding synapomorphies of the Sericini (Ahrens, 2006b). Although their exact function is not completely understood, several authors have attributed a lubrication function during copulation and oviposition. In many cases, bacteria have been reported to occur within these glands, which produce male attracting pheromones in Melolonthinae (Berberet and Helms, 1927; Stringer, 1988). Accessory glands are absent in the more ancestral lineages of Scarabaeoidea, but they are present in the herbivorous pleurostict lineages (Ahrens, 2006b). They are morphologically quite uniform among Sericini and not very stable in overall shape. However, the common duct is much shorter in Pleophylla (and possibly also in other ancestral lineages not examined yet) with the single glands being less compact in shape.

The symmetrical vaginal palps have a sensory function during copulation (Konstantinov, 1998) and are situated in the dorsal wall of the vagina composed by a single sclerite on each side; they appear to be quite uniform in shape for the whole tribe, except for a few lineages. For example, they are more elongate and sharply pointed at the apex in the Maladera castanea group, (Fig. 3Ii, Mm, Nn), while they appear (Fig. 2ET) to be slightly smaller in Pleophylla than in other groups of Sericini.

The bursa copulatrix, as a bag-like, membranous terminal extension of the female copulatory organ that receives the sperm (being ejected from the endophallus of male copulatory organ) during copulation, shows a high infraspecific variation in shape and colour depending on the female's reproductive stage at time of the collection (but also according to dissection, preparation, and preservation of the specimen) and only minor interspecific variation. The ductus bursae is in many cases also strongly sclerotised (Figs 2-3) and was therefore already used in previous studies to differentiate between female specimens of very similar and sympatrically occurring species in Gastroserica, Chrysoserica, and Gynaecoserica (Ahrens, 2000; 2001; Ahrens and Fabrizi, 2009) or for phylogenetic reconstructions of the genera Pachyserica and Serica (Ahrens, 2006a; 2007). The ductus bursae may also have additional sacs (e.g. in Pachyserica, Serica, Nepaloserica), or more undefined lateral three-dimensional extensions (e.g. in Pleophylla). Although these more or less sclerotised structures are highly informative for taxonomic and systematic purposes, they are three-dimensional and therefore difficult 

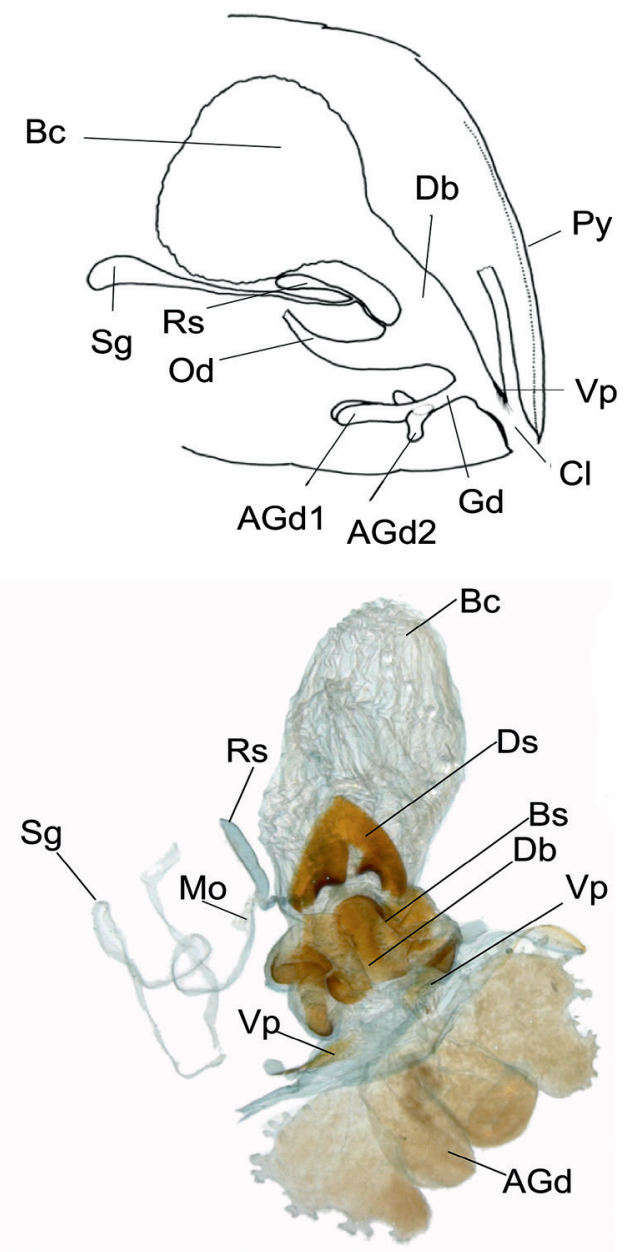

B

Fig. 1. Schematic overview on general morphology of female genitalia in Sericini. A: lateral view (schematic); B: dorsal view (Pleophylla sp.). Abbreviations: Py- Pygidium, Cl- Cloaca, Gdaccessory glands duct, Bc- Bursa copulatrix, Rs- Receptaculum seminis, Sg- Spermathecal gland, Mo- Median oviduct, VpVaginal palps, AGd- Accessory glands, Db- Ductus bursae, BsBasal sclerite, Ds- Distal sclerite.

to capture in images for comparative examination, especially for morphometric approaches. In almost all observed cases (except some Pleophylla) sclerotised structures in the ductus bursae were asymmetric.
The spermatheca, spermathecal gland and accessory gland have extremely delicate membranes and are rarely fully preserved in dry-pinned museum specimens. The wall of the spermatheca was only slightly sclerotized in most examined taxa and does not maintain a stable shape. Therefore, we could not observe much species-specific shape variation except that of their general dimensions (length and size).

Case study - Interspecific variation among Pleophylla species

Sclerotised structures in Pleophylla comprise a basal piece of the ductus bursae with a number of small lateral protuberances, and a more distal triangular sclerite (Fig. 1B, Fig. 2E-T). The latter is nearly of only two-dimensional extension and therefore also suitable for comparative analysis in terms of $2 \mathrm{D}$ morphometric analysis. At first glance (by-eye inspection), this sclerite demonstrates sufficiently stable variation among many of the species and seems to be, consequently, widely species-specific. The single lobes of the accessory glands are less compact in shape but their external outline is amorphic and irregular, a feature that has so far been found neither in any other Melolonthine chafer lineage, nor in the hypothesized sister group, Omaloplia or in any other more ancestral Sericini lineage. Consequently, this character state might constitute a synapomorphy of the genus, however, for a confirmation we need to examine a wider range of taxa of basal Sericini lineages (e.g. Astaena, Triodontella, Euronycha, Hymenoplia etc.).

The distal sclerite (Fig. 1B) can be subdivided into the following homologous portions: the (distal) apex, the median (basal) sinuation, and the internal and external basal angles. The distal apex is sharply pointed but it can be also rounded in some species. The distal sclerite is generally symmetric, and only rarely asymmetric. Most importantly, species-specific characters seem to be present in the shape of the median sinuation and of the external and internal angles. The median sinuation is in general symmetric and concave, in a few cases it is angled or asymmetric, and sometimes it

Fig. 2. Dorsal view of female copulation organ: A: Astaena sp.; B: Paratriodonta sp.; C: Omolaplia nigromarginata; D: O. erythroptera, E: Pleophylla fasciatipennis; F: P. pilosa; G: P. Sp9; H: P. ferruginea; I: P. navicularis; J: P. maculipennis; K: P. SpA1; L: P. SpM-1; M: P. SpM-10; N: P. SpM-16; O: P. SpM-17; P: P. SpM-18; Q: P. SpM-21; R: P. SpM-23; S: P. SpM-27; T: P. Sp1; U: Heteroserica sp.; V: H. sp1; W: H. sp2; X: Leuroserica lateralis; Y: Leucoserica arenicola; Z: Sericania mela; Aa: S. kashmiriensis; Bb: Cycloserica excisipes; Cc: Nepaloserica mustangia; Dd: Taiwanoserica gracilipes; Ee: S. nigroguttata; Ff: S. brevitarsis; Gg: Serica (s.str.) tukucheana; Hh: S. (s.str.) heydeni; Ii: S. (s. str.) mureensis; Jj: S. (s. str.) brunnea; Kk: S. (s. str.) thibetana; Ll: S. (s. str.) schoenmanni; Mm: S. minshanica; Nn: S. (s. str.) kingdoni. Scale bar: $0.5 \mathrm{~mm}$. 

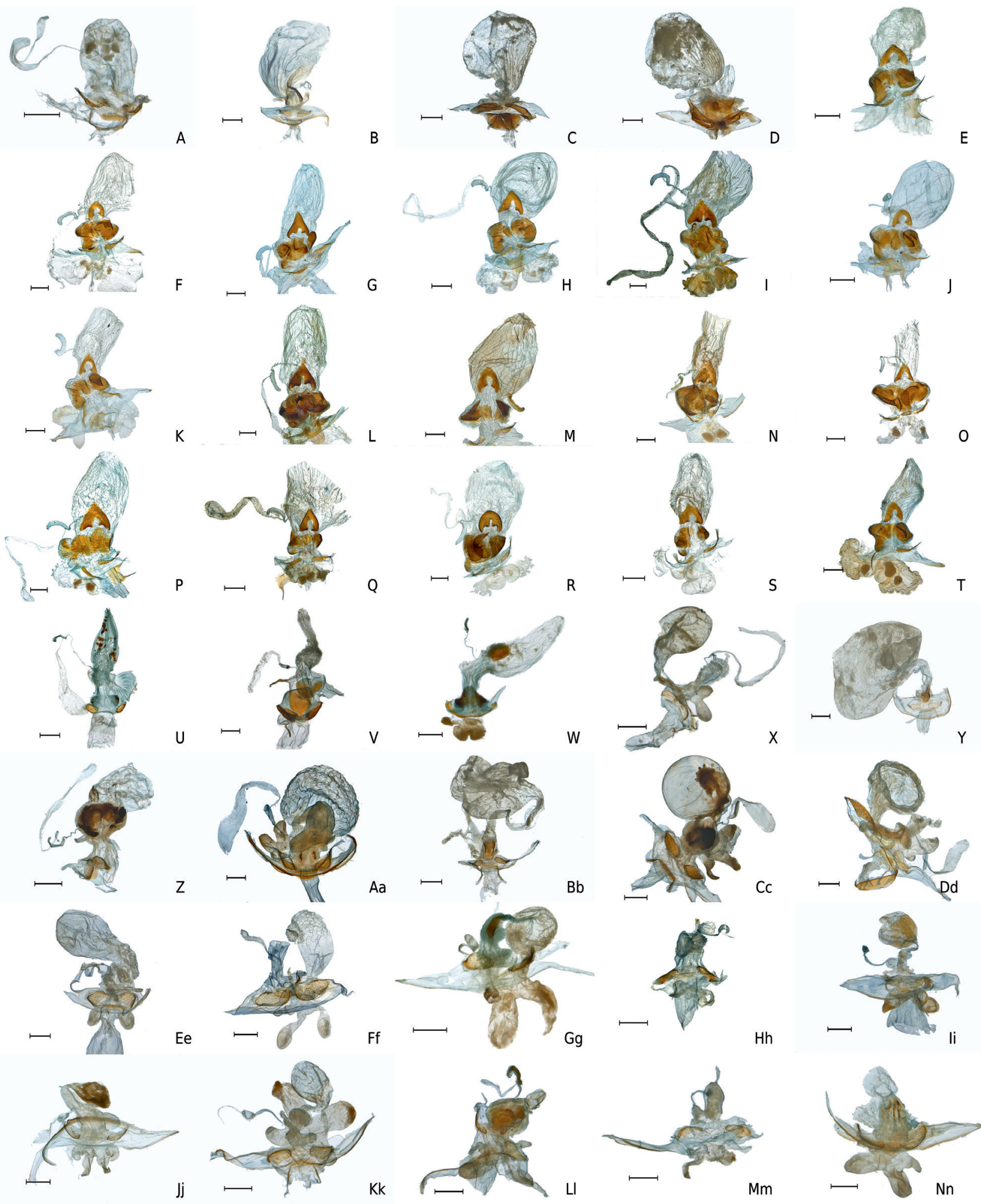

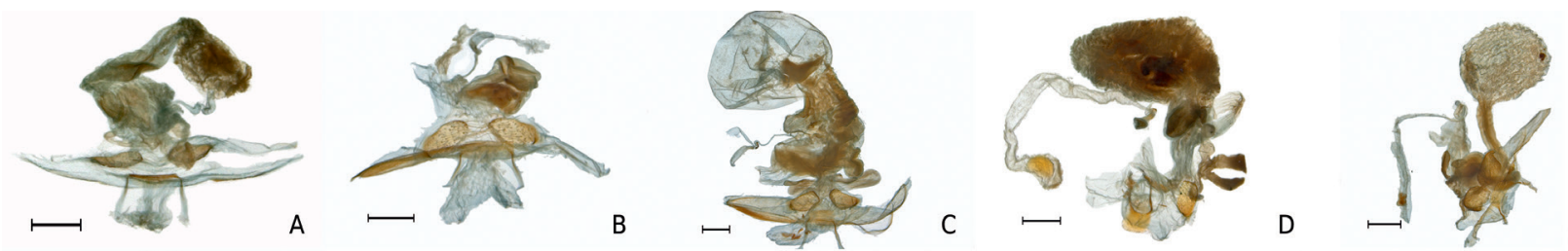

$E$
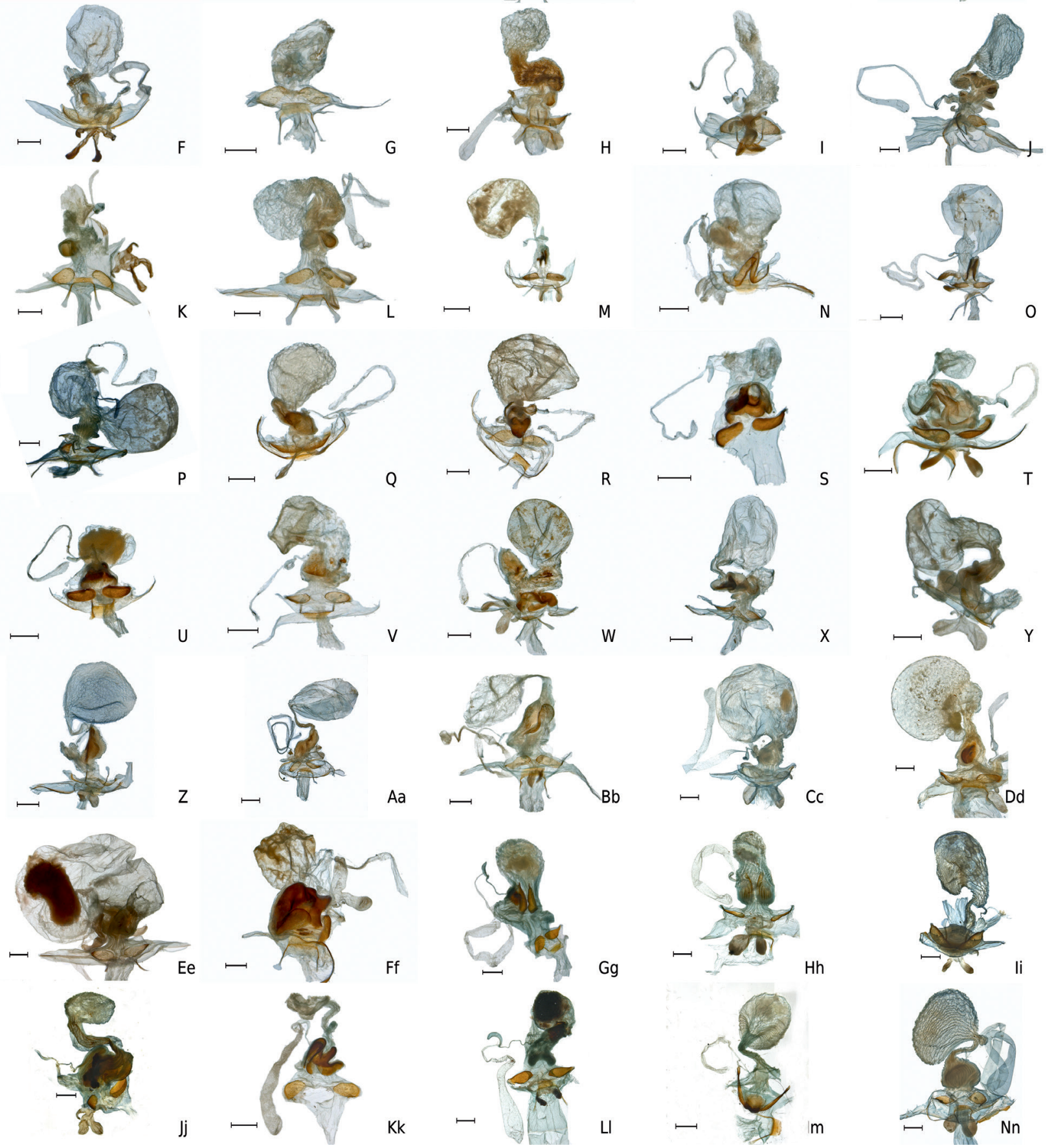

$\mathrm{Gg}$
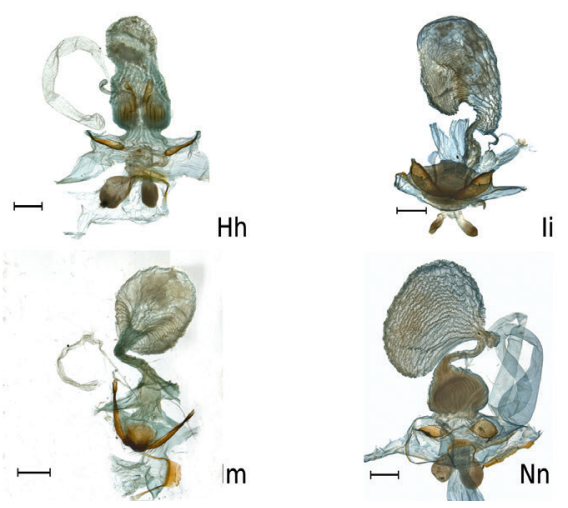
Table 1. Eigenvalues (EV) and variance (var.) of axes of Eigenshape analysis of Pleophylla specimens representing $75 \%$ of the cumulative trait variation.

\begin{tabular}{|c|c|c|c|}
\hline Axis & EV & Var. (\%) & Cumulative var. (\%) \\
\hline ES1 & 0.882 & 13.02 & 13.02 \\
\hline ES2 & 0.627 & 9.26 & 22.28 \\
\hline ES3 & 0.392 & 5.79 & 28.07 \\
\hline ES4 & 0.359 & 5.30 & 33.37 \\
\hline ES5 & 0.241 & 3.56 & 36.94 \\
\hline ES6 & 0.206 & 3.05 & 39.99 \\
\hline ES7 & 0.195 & 2.88 & 42.88 \\
\hline ES8 & 0.188 & 2.77 & 45.66 \\
\hline ES9 & 0.184 & 2.71 & 48.37 \\
\hline ES10 & 0.158 & 2.34 & 50.72 \\
\hline ES11 & 0.148 & 2.18 & 52.90 \\
\hline ES12 & 0.145 & 2.15 & 55.05 \\
\hline ES13 & 0.129 & 1.91 & 56.97 \\
\hline ES14 & 0.122 & 1.81 & 58.78 \\
\hline ES15 & 0.115 & 1.70 & 60.48 \\
\hline ES16 & 0.104 & 1.53 & 62.02 \\
\hline ES17 & 0.094 & 1.39 & 63.42 \\
\hline ES18 & 0.085 & 1.26 & 64.69 \\
\hline ES19 & 0.081 & 1.20 & 65.89 \\
\hline ES20 & 0.076 & 1.12 & 67.02 \\
\hline ES21 & 0.075 & 1.10 & 68.13 \\
\hline ES22 & 0.073 & 1.08 & 69.21 \\
\hline ES23 & 0.070 & 1.03 & 70.25 \\
\hline ES24 & 0.067 & 0.98 & 71.24 \\
\hline ES25 & 0.064 & 0.95 & 72.19 \\
\hline ES26 & 0.060 & 0.89 & 73.09 \\
\hline ES27 & 0.058 & 0.85 & 73.95 \\
\hline ES28 & 0.057 & 0.84 & 74.79 \\
\hline ES29 & 0.056 & 0.82 & 75.62 \\
\hline
\end{tabular}

is additionally provided with a thin sclerotised membrane. The depth and width of the median sinuation show a great variation between the different species.

The shape of the distal sclerites distinguished many, but not all of the species. In the Standard Eigenshape analysis the first 29 Eigenshape (ES) axes represented $75 \%$ and the first $67 \mathrm{ES}$ axes $95 \%$ of the cumulative variance of the shape of the sclerotised area (Table 1). CVA analysis based on the first $67 \mathrm{ES}$ axes provided a good separation between many species, but not all.
Plots of some species were still partly or also widely overlapping when all species were analyzed together (Fig. 4) showing only little divergence between those species. Clear morphological gaps were almost not visible.

\section{Asymmetry}

Asymmetry is found in most of the examined Sericini species, either in the bursa copulatrix only, or in both the bursa copulatrix and ductus bursae. Asymmetry comprises sclerotised and non-sclerotised structures and is only less pronounced in more ancestral lineages with a symmetrical or weakly asymmetrical male aedeagus like Astaena, Pleophylla and Triodontella (Fig. 2A-T). In the genus Omaloplia, with strongly asymmetric aedeagus we found only little to no asymmetry in the membranous bursa copulatrix (sclerotised structures are absent in this group, Fig. 2C,D). In most of the modern Sericini (i.e. redefined subtribe Sericina, Ahrens, 2006b), sclerotised structures are often developed in the ductus bursae that in most cases were highly asymmetric (Figs $2 \mathrm{X}-3 \mathrm{Nn}$ ). This asymmetry is linked to strong asymmetry of the male copulation organ in all cases examined (Ahrens and Lago, 2008). Given that we found female and male asymmetry for almost all species examined, it is possible that male and female asymmetry is present in the majority of the species of the tribe, which includes nearly 4000 species.

\section{Discussion}

\section{Utility of female genitalia for taxonomy and systematics}

This preliminary study revealed significant taxonomic (and also likely phylogenetic) value of female genital traits despite a very limited sampling from the very diverse group of Sericini beetles. Our observations indicate a vast diversity in the shapes of sclerites of the ductus bursae (see Figs 2-3) that seem suitable for use in species-level taxonomy. Stable interspecific variation is

Fig. 3. Dorsal view of female copulation organ: A: Pachyserica mamorata; B: P. nantouensis; C: Pachyserica olafi; D: P. albosquamosa; E: P. bistriata; F: P. horrida; G: P. subpilosa; H: P. himalayensis; I: P. gracilis; J: P. jendeki; K: P. nepalica; L: P. ambiversa; M: Gynaecoserica cymosa; N: G. variipennis; O: G. lobiceps; P: G. singhikensis; Q: Lasioserica maculata; R: L. nobilis; S: L. brevipilosa; T: Lasioserica petri; U: Amiserica patibilis; V: Amiserica rejseki; W: Amiserica flavolucida; X: Amiserica costulata; Y: Amiserica krausei; Z: Neoserica (s.str.) tamdaoensis; Aa: N. (s.str.) ursina; Bb: N. (s.str.) pseudovulpina; Cc: Chrysoserica sp.; Dd: C. auricoma; Ee: C. stebnickae; Ff: Calloserica langtangica; Gg: Eumaladera sp.; Hh: S. brunnescens; Ii: Maladera affinis; Jj: Maladera sp.; Kk: Maladera sp809; Ll: M. cruralis; Mm: M. verticalis; Nn: M. hongkongica. Scale bar: 0.5 mm. 


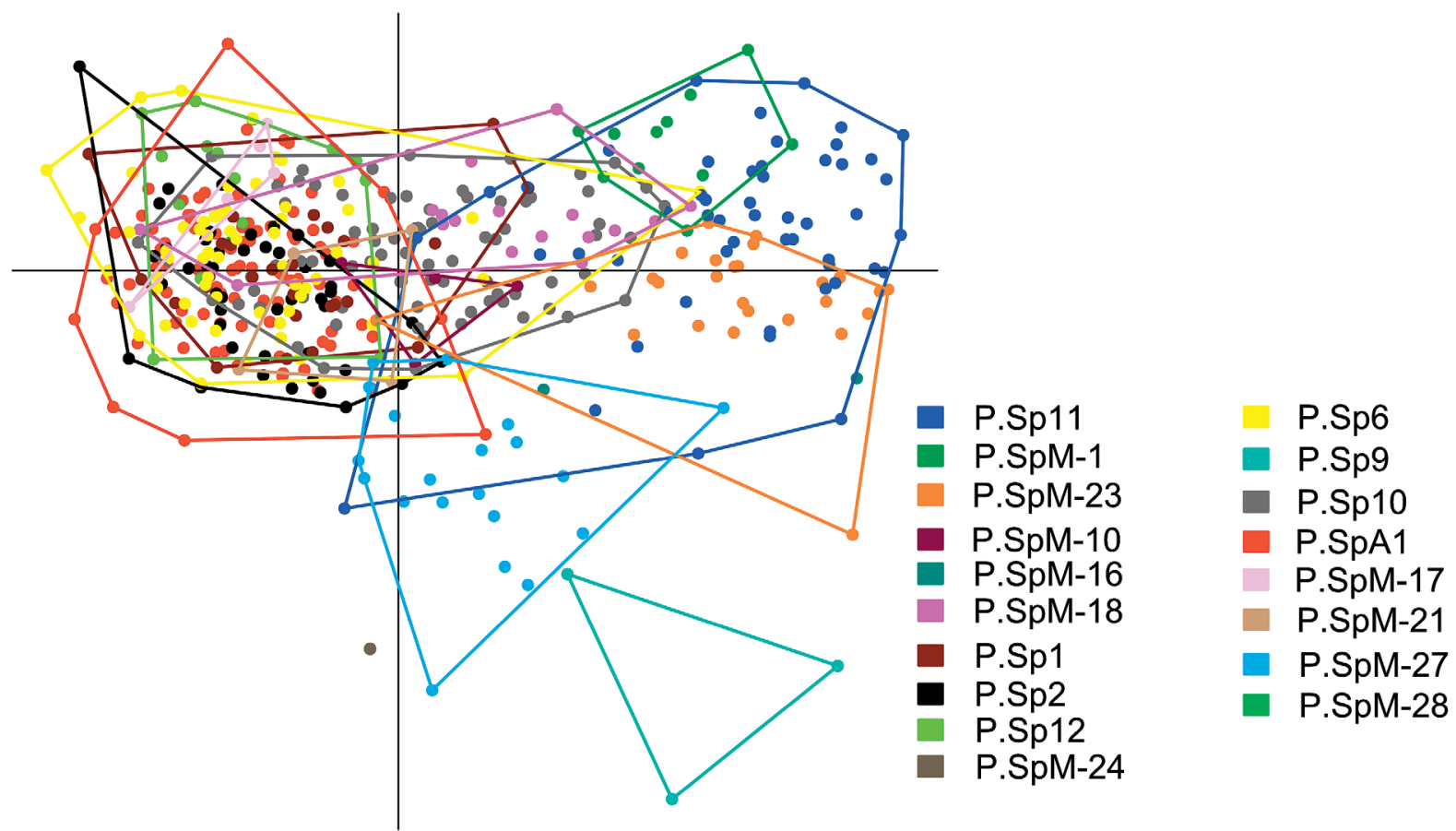

Fig. 4. Results of shape analysis of the genus Pleophylla: Plot of axes 1 and 2 of Cannonical Variate Analysis from Eigenshape analysis.

rarely discernable in the shape and size of vaginal palps and all other membranous structures such as the shape of the bursa copulatrix (see the problems mentioned above). The same applies for the spermatheca and the spermathecal gland, which can vary in size and proportions, but to verify robust differences among the species requires well-preserved specimens and a larger sampling per species to detect also species-constant characteristics. The more detailed examination and quantitative shape analysis of the genus Pleophylla consisting of many very similar species that are difficult to distinguish by external morphology showed the importance of investigating both, speciesspecific male and female genitalia in order to revalidate morphology. Pleophylla appears to be a young radiation and most male specimens differ very significantly in the shape of parameres (Warnock, 2009). Their female genitalia are species-specific in most but not all of the species, but for many pair-wise species comparisons they provide a useful trait to be used to distinguish between the species (Fig. 4).

\section{Symmetry and asymmetry}

Based on evidence in various insect groups, Huber et al. (2007) concluded that asymmetries in insect taxa tend to evolve first in male genitalia, while female asymmetries evolve later or not at all. The evolutionary sequence of genital asymmetry (male-first or male-only asymmetry) is crucial to understand patterns of asymmetry and to infer explanations for asymmetry (Schilthuizen, 2013). In most scarab beetles, male external genitalia are symmetrical (D'Hotman and Scholtz, 1990). The male genitalia of the presumptive sister group of Sericini (i.e. Ablaberini) as well of all more ancestral lineages (i.e. Southern World Melolonthinae; Ahrens and Vogler, 2008) are symmetrical, too. However, the morphological inaccessibility and lack of hard tissues means that female genitalia morphology is generally less well-studied and rarely used for taxonomic questions (Eberhard, 1985; Huber, 2010; Ah-King et al., 2014), also in these mentioned groups. Therefore, some patterns of apparent 'male first' evolution may actually reflect a lack of knowledge of the female genitalia rather than a real evolutionary trend, which is a general problem in research on insect genitalia (Brennan et al., 2007; Huber et al., 2007), or might indicate the need to date (and investigate) such events at a much earlier stage when asymmetry in external genitalia was not apparent yet.

Our results presented here on symmetry/ asymmetry of female genitalia of Sericini are based exclusively 
on a qualitative level. We refrained from a quantitative assessment of asymmetry of female genitalia (under the current sampling) for two major reasons: 1) From dissections of multiple specimens (at least 2 per species), we realised that the inclination and shape (degree of expansion) of bursa copulatrix (due to mounting artefacts and status of female in reproduction cycle) varied within species to a quite large extent, which would not allow the disentangling between true shape variation and artefacts or life cycle bias. This would strongly hamper the estimate of interspecific variation of asymmetry. 2) Asymmetric structures comprise mainly the shape of the ductus bursae and the bursa copulatrix. Asymmetry of the latter is hard to measure from shape (see 1) while more significant asymmetric structures like sclerotisations within the ductus bursae are difficult to homologize. Consequently, in many cases we would not know what we compare exactly.

Nevertheless, our findings have shown that the megadiverse Sericini has achieved a complex and long evolutionary history of male-female genital asymmetry. This might indicate that the shift to asymmetry is phylogenetically highly conservative. It seems that selection is stabilising the once acquired asymmetry in many different lineages within such a large group. Conclusions from patterns of asymmetry variation in male versus female genitalia should be drawn with caution. The bursa copulatrix and other soft tissue parts may be damaged easily during preparation, which might strongly bias the morphological observations. On the other hand, the endophallus has not yet been studied comparatively in scarab beetles in general, nor in Sericini. Therefore our knowledge on the 'true' copulating structures is to be considered to be still very fragmentary. For this reason, we limited our investigation here to a qualitative (and subjective) assessment of degree of apparent symmetry of the corresponding external male genitalia that are introduced only partly in the female reproductive tract in most chafers (Eberhard, 1993; Krell, 1996). Nevertheless, we may conclude from the current observations that more asymmetric external male genitalia seem to be linked with more asymmetric female genitalia.

A first step to investigate the correlation between male and female asymmetry more thoroughly, in particular for beetles, would be to focus studies on the shape of the male endophallus in everted state (rather than only the sclerotized structures of it; e.g. Tarasov and Solodovnikov, 2011) and to establish female genitalia, where possible, also as a standard diagnostic feature for species taxonomy. The latter would widen the extent of the morphological knowledge on female genitalia and would allow more easily for an observation of male-female asymmetry correlation. Modern DNA taxonomy approaches might greatly enhance this task given the frequent difficulty of identification of female specimens (e.g. Ahrens et al., 2007). Beyond facilitating a more integrative taxonomic approach (Padial et al., 2010; Yeates et al., 2011), this would also allow a better observation of infraspecific variation and help to find exceptions from the 'default' male-female asymmetry of the group, especially where asymmetry is only weak. In this context, interesting study cases might be lineages with reversal to symmetric aedeagi, such as encountered in certain Asian lineages of Sericini (e.g. Oxyserica, Nipponoserica, some taxa of Maladera). We would need to investigate the state of symmetry of these lineages' female genitalia, and whether males constitute 'crypto-asymmetric' lineages (externally symmetric, internal structures and/or endophallus asymmetric), as found for the dynastine beetle genus Cyclocephala (Breeschoten et al., 2013).

A second step to investigate the evolution of genitalic asymmetry further would be to place developments of asymmetry (male and/or female) in a robust phylogenetic context (e.g., Breeschoten et al., 2013). That requires, however, in the case of the Sericini, a very comprehensive sampling, as shifts from symmetry to asymmetry seem to occur at quite early stages of the evolution of the group. Probably, the reversal from (apparent) asymmetry to symmetry (or cryptic asymmetry) would be the more interesting case to investigate (see above), while groups like Cyclocephala (Breeschoten et al., 2013), or Schizonycha (Pope, 1960), where within one genus symmetric and asymmetric external male genitalia occur, seem to be more suitable and promising to discover mechanisms that lead to asymmetry in the genitalia (in chafer beetles). The gradual shift from symmetric to asymmetric forms found by Breeschoten et al. (2013), if reconfirmed also for other groups, might be a very important key to understand better the mechanisms of selection leading to asymmetry and of conserving it.

Here we have reported asymmetry in the female genitalia for the first time among scarab beetles (for a large number of species). Circumstances for this group of beetles suggest that only sexual selection may have driven asymmetric male-female genital co-evolution in this group, but evidence for such a hypothesis is still not available. Therefore, the study the evolution of asymmetric genitalia (Schilthuizen and Gravendeel, 2012; Schilthuizen, 2013) should be one major focus 
for future investigations of genital evolution and the evolutionary drivers of their morphological diversity.

\section{Acknowledgements}

We are grateful to Manfred Uhlig, Riaan Staals, Ruth Müller and James Harrison for loan and permission of dissection of their museum specimens. For providing D.A. with research and collection permits for South African Sericini, we thank the various governmental institutions and departments in Eastern Cape (Permit No.: WRO 122/07WR and WRO123/07WR), Gauteng (Permit No.: CPF6 1281), Limpopo (Permit No.: CPM006-00001), Mpumalangma (Permit No.: MPN-2009-11-201232), and Kwazulu-Natal (Permit Nos OP3752/2009, 1272/ 2007, 3620/2006). We thank Greg Holwell as well as one other anonymous referee who helped to improve the final version of the manuscript. The study was supported by the German Science Association (DFG; AH/175/3).

\section{References}

Ah-King M, Barron AB, Herberstein ME. 2014. Genital Evolution: Why are females still understudied? PLoS Biology 12: e1001851. doi: 10.1371/journal.pbio.1001851.

Ahrens D. 2000. Synopsis der Gattung Gastroserica Brenske, 1897 des ostasiatischen Festlandes (Coleoptera: Melolonthidae: Sericini). Entomologische Abhandlungen 59(3): 73-121.

Ahrens D. 2001. Zwei neue Chrysoserica-Arten aus dem Himalaya. (Coleoptera, Melolonthidae). Bolletino della Società Entomologia 133: 133-147.

Ahrens D. 2006a. Revision und phylogenetische Analyse der Gattung Pachyserica Brenske, 1897 (Coleoptera, Melolonthidae, Sericini). Revue Suisse de Zoologie 113: 487-557.

Ahrens D. 2006b. The phylogeny of Sericini and their position within the Scarabaeidae based on morphological characters (Coleoptera: Scarabaeidae). Systematic Entomology 31: 113-144.

Ahrens D. 2007. Beetle evolution in the Asian highlands: insight from a phylogeny of the scarabaeid subgenus Serica (Coleoptera, Scarabaeidae). Systematic Entomology 32: 450-476.

Ahrens D, Fabrizi S. 2009. A review on the genus Gynaecoserica Brenske, 1897 (Coleoptera, Scarabaeidae, Sericini). Journal of Natural History 43: 1505-1584.

Ahrens D, Lago PK. 2008. Directed asymmetry reversal of male copulatory organs in chafer beetles (Coleoptera: Scarabaeidae) - implications on left-right polarity determination in insect terminalia. Journal of Zoological Systematics and Evolutionary Research 46: 110-117.

Ahrens D, Vogler AP. 2008. Towards the phylogeny of chafers (Sericini): analysis of alignment-variable sequences and the evolution of segment numbers in the antennal club. Molecular Phylogenetics and Evolution 47: 783-798.

Ahrens D, Monaghan MT, Vogler AP. 2007. DNA-based taxonomy for associating adults and larvae in multi-species assemblages of chafers (Coleoptera: Scarabaeidae). Molecular Phylogenetics and Evolution 44: 436-449.
Ahrens D, Scott M, Vogler AP. 2011. A phylogeny of monkey beetles based on mitochondrial and ribosomal DNA (Coleoptera: Scarabaeidae: Hopliini). Molecular Phylogenetics and Evolution 60: 408-415.

Arnqvist G, Thornhill R. 1998. Evolution of animal genitalia: patterns of phenotypic and genotypic variation and condition dependence of genital and non-genital morphology in water strider (Heteroptera: Gerridae: Insecta). Genetical Research 71: 193-212.

Barratt BIP, Campbell RA. 1982. Biology of the striped chafer. Odontria striata (Coleoptera: Scarabaeidae) 1. The adult. flight and ground surface activity, female reproductive maturation, and food-plant selection. New Zealand Journal of Zoology 9: 249-266.

Berberet RC, Helms TJ. 1972. Comparative anatomy and histology of selected systems in larval and adult Phyllophaga anxia (Coleoptera: Scarabaeidae). Annals of the Entomological Society of America 65: 1026-1053.

Brennan PLR, Prum RO, McCracken KG, Sorenson MD, Wilson RE, Birkhead TR. 2007. Coevolution of male and female genital morphology in waterfowl. PloS ONE 2: e418.

Breeschoten T, Clark DR, Schilthuizen M. 2013. Evolutionary patterns of asymmetric genitalia in the beetle tribe Cyclocephalini (Coleoptera: Scarabaeidae: Dynastinae). Contributions to Zoology 82: 95-106.

Coca-Abia M, Martin-Piera F. 1991. Anatomy and morphology of the genitalia in the subtribe Rhizotrogini (Col. Melolonthidae, Melolonthini): taxonomic implications. Pp. 61-78 in: Zunino M, Belles X, Blas M, eds, Advances in Coleopterology.

Coca-Abia MM, Robbins PS. 2006. Taxonomy and phylogeny of a new Central American beetle genus: Catrachia (Coleoptera: Scarabaeidae). Revista de Biología Tropical 54: 519-529.

Coca-Abia M, Martin-Piera F, Moron MA. 1993. Anatomia y morfologa de la genitalia femminina de las especies mexicanas del genero Phyllophaga (sensu lato) (Coleoptera, Melolonthidae). Relaciones filogeneticas con otros generos del area mediterranea. Giornale Italiano di Entomologia 6 (33): 263-274

Cordoba-Aguilar A. 2010. The evolution of primary sexual characters in animals: a summary. Pp. 494-497 in: Leonard J, Cordoba-Aguilar A, eds, The evolution of primary sexual characters in animals. Oxford: Oxford University Press.

Dajoz R. 1972. Biologie et anatomie de Scarabaeus semipunctatus F. (Coleoptera, Scarabaeidae). Comparaison avec quelques autres Coleopteres coprophages. Cahiers des Naturalistes. Bulletin des Naturalistes Parisiens, nouvelle serie 28: 61-79.

D'Hotman D, Scholtz CH. 1990. Phylogenetic significance of the structure of the external male genitalia in the Scarabaeoidea (Coleoptera). Entomology Memoir, Department of Agricultural Development 77: 1-51.

Dupuis F. 2005. L'abdomen et les genitalia des femelles de coléoptères Scarabaeoidea (Insecta, Coleoptera). Zoosystema 27: 733 .

Eberhard WG. 1985. Sexual selection and animal genitalia. Harvard University Press.

Eberhard WG. 1993. Copulatory courtship and genital mechanics of three species of Macrodactylus (Coleoptera Scarabaeidae Melolonthinae). Ethology, Ecology \& Evolution 5: 19-63. 
Eberhard WG. 1996. Female control: sexual selection by cryptic female choice. Princeton University Press.

Hammer $\varnothing$, Harper DAT, Ryan PD. 2001. PAST: Paleontological statistics software package for education and data analysis. Paleontologia Electronica 4: 1-9.

Heymons R. 1930. Über die Morphologie des weiblichen Geschlechtsapparats der Gattung Scarabaeus L. Zeitschrift für Morphologie und Ökologie der Tiere 18: 536-574.

Hosken DJ, Stockley P. 2004. Sexual selection and genital evolution. Trends in Ecology and Evolution 19: 87-93.

Huber BA. 2010. Mating positions and the evolution of asymmetric insect genitalia. Genetica 138: 19-25.

Huber BA, Sinclair, BJ, Schmitt M. 2007. The evolution of asymmetric genitalia in spiders and insects. Biological Reviews 82: 647-698.

Imelda Martinez M, Trotta-Moreu N. 2010. Comparative study of Mexican Geotrupini (Coleoptera: Scarabaeoidea: Geotrupidae) reproductive systems, with taxonomic commentaries. The Coleopterists Bulletin 64: 129-140.

Konstantinov AS. 1998. On the structure and function of the female genitalia in flea beetles (Coleoptera: Chrysomelidae: Alticinae). Proceedings of the Entomological Society of Washington 100: 353-360.

Krause JB. 1947. The development of the gonads of the woodeating beetle, Passalus cornutus Fabricius. Annals of the Entomological Society of America 40: 172-202.

Krell FT. 1996. Die Kopulationsorgane des Maikafers Melolontha melolontha (Insecta: Coleoptera: Scarabaeidae). - Ein Beitrag zur vergleichenden und funktionellen Anatomie der ektodermalen Genitalien der Coleoptera. Stuttgarter Beiträge zur Naturkunde Serie A 537: 1-101.

Lohmann GP. 1983. Eigenshape analysis of microfossils: A general morphometric procedure for describing changes in shape. Journal of the International Association for Mathematical Geology 15: 659-672.

Lohmann GP, Schweitzer PN. 1990. On Eigenshape Analysis. Pp. 166 in: Proceedings of the Michigan Morphometrics Workshop. Ann Arbor, MI: University of Michigan Museum of Zoology 145.

Martin-Piera F. 1992. El valor taxonómico y sistemático de la genitalia en los Scarabaeoidea (Coleoptera). Elytron 6: 233239.

Mayr E. 1963. Animal species and evolution. Animal species and their evolution. Cambridge, MA: Harvard University Press.

McLeod N. 1999. Generalizing and extending the eigenshape method of shape space visualization and analysis. Paleobiology 25: 107-138.

Mendez V, Cordoba-Aguilar A. 2004. Sexual selection and animal genitalia. Trends in Ecology and Evolution 19: 224-225.

Menees JH. 1963. Embryonic and postembryonic homologies of insect genitalia as revealed in development of male and female reproductive systems of European chafer, Amphimallon majalis Razoumowski (Coleoptera: Scarabaeidae). Cornell University Experimental Station, Memoir 381: $59 \mathrm{pp}$.

Micó E, Galante E. 2000. The internal ectodermic genitalia of iberian Anisopliini (Coleoptera: Scarabaeoidea: Rutelidae). Elytron 14: 53-67.

Padial J, Miralles A, De la Riva, I, Vences M. 2010. The integrative future of taxonomy. Frontiers in Zoology 7: 16.
Polihronakis M. 2007. Generic guide to New World Scarab beetles: Gemnus Phyllophaga. http://museum.unl.edu/research/ entomology/Guide/Scarabaeoidea/Scarabaeidae/Melolonthinae/Melolonthinae-Generic-pages/Melolonthini/Phyllophaga/Phyllophaga.html

Pope RD. 1960. A Revision of the Species of Schizonycha Dejean (Col.: Melolonthidae) from Southern Africa. Bulletin of the Natural History Museum 9 (2): 63-218.

Ritcher PO. 1966. White grubs and their allies: a study of North American scarabaeoid larvae. Oregon State Monographs. Studies in Entomology. Oregon State University Press, Corvallis.

Riley EG, Wolfe CS. 1995. A review of the Phyllophaga ignava species group with descriptions of two new species from Texas (Coleoptera: Scarabaeidae; Melolonthinae). Journal of the New York Entomological Society 103: 421-434.

Rohlf FJ. 2006. tpsDig, Version 2.10. Department of Ecology and Evolution, State University of New York, Stony Brook.

Schilthuizen M. 2013. Something gone awry: unsolved mysteries in the evolution of asymmetric animal genitalia. Animal Biology 63: 1-20.

Schilthuizen M, Gravendeel B. 2012. Left-right asymmetry in plants and animals: a gold mine for research. Contributions to Zoology 81: 75-78.

Sharp D, Muir FAG. 1912. The comparative anatomy of the male genital tube in Coleoptera. Transactions of the Entomological Society London 1912 (3): 477-642, plts. XLII-LXXVIII.

Simmons LW. 2014. Sexual selection and genital evolution. Austral Entomology 53: 1-17.

Smith ABT. 2006 A review of the family-group names for the superfamily Scarabaeoidea (Coleoptera) with corrections to nomenclature and a current classification. Coleopterists Society Monographs 5: 144-204.

Stein F. 1847. Vergleichende Anatomie und Physiologie der Insekten. I. Monographie. Über die Geschlechtsorgane und Bau des Hinterleibes bei den weiblichen Käfern. Berlin, Danker und Humbolt. 139pp.

Straus-Dürckheim HEG. 1828. Considérations Générales Sur L'anatomie Comparée Des Animaux Articulés, Auxquelles on a Joint L'anatomie Descriptive Du Melolontha Vulgaris (Hanneton), Donnée Comme Exemple de L'organisation Des Coléeptères. Paris, Strasbourg, Bruxelles, F.G. Levrault. 9: 434pp.+36pp.

Stringer IAN. 1988. The female reproductive system of Costelytra zealandica (White) (Coleoptera: Scarabaeidae: Melolonthinae). New Zealand Journal of Zoology 15: 513-533.

Tanner VM. 1927. A preliminary study of the genitalia of female Coleoptera. Transactions of the American Entomological Society 53(1): 5-50.

Tarasov SI, Solodovnikov AY. 2011. Phylogenetic analyses reveal reliable morphological markers to classify mega-diversity in Onthophagini dung beetles (Coleoptera: Scarabaeidae: Scarabaeinae). Cladistics 27: 490-528.

Warnock R. 2009. A comparation between species delination based on DNA sequences and genital morphometrics in beetles (Coleoptera). Master of Science thesis, Imperial College London.

Watt JI. 1971. Entomology of the Aucklands and other islands south of New Zealand: Coleoptera: Scarabaeidae, Byrrhidae, Ptinidae, Tenebrionidae. Pacific Insects Monographs. 27: 193-224. 
Wojcieszek JM, Simmons LW. 2013. Divergence in genital morphology may contribute to mechanical reproductive isolation in a millipede. Ecology and Evolution. 3: 334-343.

Woodruff RE, Sanderson MW. 2004. Revision of the Phyllophaga of Hispaniola (Coleoptera: Scarabaeidae: Melolonthinae). Insecta Mundi 18: 1-22.

Williams IJ. 1945. The anatomy of the internal genitalia of some Coleoptera. Proceedings of the Entomological Society of Washington 47: 73-91.

Willimzik E. 1930. Über den Bau der Ovarien verschiedener Coprophager Lamellicornier und ihre Beziehung zur Brutpflege. Zoomorphology 18: 669-70.

Yassin A, Orgogozo V. 2013. Coevolution between male and female genitalia in the Drosophila melanogaster species subgroup. PlosOne 8: e57158.

Yeates, DK, Seago A, Nelson L, Cameron SL, Joseph L, Trueman JW. 2011. Integrative taxonomy, or iterative taxonomy? Systematic Entomology 36: 209-217.
Zorn C. 2011. New species of the genus Anomala Samouelle from mainland South East Asia and South China (Coleoptera: Scarabaeidae: Rutelinae). Stuttgarter Beiträge zur Naturkunde A, Neue Serie 4: 297-312.

Zunino M. 1971. Importanza dell'apparato genitale femminile nella sitematica del genere Onthophagus Latr. (Coleoptera, Scarabaeoidea). Bolletino della Societa entomologica Italiana 103: 26-31.

Zunino M. 1972. Revisione della specie paleartiche del genere Onthophagus Latr. (Col.Scar.) 1. Il sottogenere Euonthophagus Balth. Bolletino del Museo Zoologico della Universita di Torino 1972(1): 1-27.

Received: 17 August 2014

Revised and accepted: 3 February 2015

Published online: 4 August 2015

Editor: M. Schilthuizen 